\title{
MARCO LEGAL ARGENTINO SOBRE ASISTENCIA RELIGIOSA CASTRENSE. FUNCIONALIDAD Y NECESIDAD DE LA EXISTENCIA DE DICHA POLÍTICA LEGISLATIVA. FUNDAMENTOS SOCIOLÓGICOS Y FILOSÓFICOS
}

\section{[Argentinian legal framework on religious assistance in the armed forces. Rational and requirements of the existence of such as legislative policy. Sociological and philosophical justifications]}

\author{
EL ETER, LEANDRO ${ }^{1}$
}

\begin{abstract}
Resumen
La presente investigación estriba en el análisis del marco jurídico argentino en la asistencia religiosa castrense. Se indaga acerca de la historicidad, filosofía y legalidad del instituto de referencia. Del mismo modo, se ahonda en su funcionalidad y necesidad de implementación dentro de la órbita de las fuerzas armadas, y se crítica a las posiciones detractoras de la asistencia religiosa por considerarse que carecen de fundamentos y justificaciones sociológicas y jurídicas. El sentido del estudio es mostrar cómo la asistencia religiosa ha permitido fomentar el desarrollo espiritual de la persona, superando una visión estrictamente materialista y economicista.

Palabras claves: ley, asistencia, religiosa, castrense, cuerpo, alma

Abstract

The present investigation is based on the analysis of the Argentine legal framework in military religious assistance. It inquires about the historicity, philosophy and legality of the reference institute. Likewise, it deepens in its functionality and the need to implement it within the orbit of the armed forces, and criticizes the positions that detract from religious assistance as they are considered to lack sociological and legal foundations and justifications. The sense of the study is to show how religious assistance has allowed promoting the spiritual development of the person, overcoming a strictly materialistic and economistic vision.
\end{abstract}

Key Words: law, assistance, religious, military, body, soul

DOI: 10.7764/RLDR.10.122

\footnotetext{
${ }^{1}$ Abogado. Profesor de Derecho, Facultad de Ciencias Jurídicas, Políticas y Sociales de la Universidad del Norte Santo Tomás de Aquino (UNSTA), Argentina. E-mail: leandroeleter@yahoo.com.ar / estudioeleter@yahoo.com
} 
Leandro El Eter: Marco legal argentino sobre asistencia religiosa castrense. Funcionalidad y necesidad de la existencia de dicha política legislativa. Fundamentos sociológicos y filosóficos

\section{INTRODUCCIÓN}

La libertad religiosa ha sido, desde la época de la organización del Estado Argentino, un elemento esencial para la configuración de una sociedad plural. La noción de democracia y de república se construyen con la presencia de la libertad como valor. De hecho, la revolución francesa de 1789 proclama como principios a la libertad, la igualdad y la fraternidad (dicha herencia europea sustenta la razón de ser del sistema político latinoamericano).

Además, cabe subrayar que la influencia católica del colonialismo español fue receptada en la región y fundamentó el sustento de la creencia cristiana y de sus valores.

No es extraño que las fuerzas armadas argentinas y latinoamericanas hayan construido sus ideales de acuerdo a las creencias cristianas. Próceres tales como Manuel Belgrano, José de San Martín y Simón Bolívar han sido fervientes creyentes del catolicismo y han construido las bases de las naciones con sustento en valores cristianos. Los movimientos políticos con epicentro en Europa fueron motivadores de la naturaleza del sistema castrense vigente.

La Constitución Nacional Argentina consagra el derecho a profesar libremente cualquier culto conforme a las leyes que reglamenten su ejercicio, tal como lo indica el artículo 14 . La ley de leyes posibilita que cualquier argentino pueda practicar cualquier culto. Es preciso mencionar que existe un Registro Nacional de Cultos dentro de la órbita de la Secretaria de Estado de Culto dependiente del Ministerio de Relaciones Exteriores y Culto de la Nación. 
Leandro El Eter: Marco legal argentino sobre asistencia religiosa castrense. Funcionalidad y necesidad de la existencia de dicha política legislativa. Fundamentos sociológicos y filosóficos

Además, las Constituciones Provinciales y los tratados internacionales con jerarquía constitucional prevén la protección de la libertad de culto.

El Poder Ejecutivo Nacional asegura la libertad religiosa de las personas, tanto en forma individual o colectiva, pública o privada, con los únicos límites de la moral, las buenas costumbres, el orden público, la seguridad, la salud pública, el bienestar general y los derechos de los demás ciudadanos. Las restricciones mencionadas obedecen a cuestiones que contribuyen con el bienestar general. No puede prescindirse del orden público como parámetro imprescindible para incentivar un correcto y equilibrado ordenamiento jurídico dirigido a un bien superior denominado "bien común".

En la "Declaración sobre la eliminación de todas las formas de intolerancia y discriminación fundadas en la Religión o las convicciones" de la Organización de las Naciones Unidas (Resolución 36/55) se establece en su artículo 4.1 que "Todos los Estados adoptarán medidas eficaces para prevenir y eliminar toda discriminación por motivos de religión o convicciones en el reconocimiento, el ejercicio y el goce de los derechos humanos y de las libertades fundamentales en toda las esferas de la vida civil, económica, política, social y cultural". A su vez, el artículo 4.2 declara que "Todos los Estados harán todos los esfuerzos necesarios para promulgar o derogar leyes, según el caso, a fin de prohibir toda discriminación de ese tipo y por tomar las medidas adecuadas para combatir la intolerancia por motivos de religión o convicciones en la materia". Dichos artículos no necesitan mayor análisis porque es importante destacar que ninguna religión fomenta la discriminación sino todo lo contrario y, en definitiva, todas las religiones humanizan a la persona como ser humano. En cierta medida, existen puntos de encuentro entre las diferentes creencias, donde se fomenta una convivencia social armoniosa y justa.

Lo expuesto muestra que la libertad religiosa está reconocida a todos los habitantes, de forma personal y colectiva, tanto en la Constitución Nacional como en los Tratados Internacionales con jerarquía constitucional. Tanto la Carta Magna como dichos Tratados 
Leandro El Eter: Marco legal argentino sobre asistencia religiosa castrense. Funcionalidad y necesidad de la existencia de dicha política legislativa. Fundamentos sociológicos y filosóficos

constituyen las normas máximas de la pirámide jurídica y por consiguientes, las leyes inferiores se subordinan a las mismas.

El personal de las fuerzas armadas, policiales y de seguridad federales cuenta con asistencia religiosa en distintos actos, eventos y ceremonias oficiales por parte del Culto Católico Apostólico Romano. Dicho culto, aunque es el predominante tanto en el territorio nacional como en las fuerzas armadas, policiales y de seguridad federales, no es el único profesado por los miembros de las fuerzas. Si bien existe un predominio del cristianismo, cualquier agente puede profesar otra religión o decidir no contar con ningún tipo de asistencia religiosa. Los individuos que se consideran ateos son respetados por su forma de concebir la realidad y no se encuentran obligados a tener una asistencia espiritual. Dicho de otra manera, el respeto a las diferencias y a la diversidad y la tolerancia se han convertido en valores prácticamente reconocidos de manera universal.

Desde un enfoque imparcial, la construcción de la hipótesis se estructura en relación a las exposiciones teóricas propuestas. A tal punto, se afirma que "la asistencia religiosa castrense es una expresión de la identidad nacional y su permanencia se centra en una necesidad espiritual ".

\section{NOCIÓN Y RAZÓN DE SER DE LA ASISTENCIA RELIGIOSA CASTRENSE ARGENTINA DENTRO DE LA ÓRBITA DEL DERECHO ECLESIÁSTICO. ¿LA ASISTENCIA RELIGIOSA FORMA PARTE DE LA IDENTIDAD DE LA NACIÓN?}


Leandro El Eter: Marco legal argentino sobre asistencia religiosa castrense. Funcionalidad y necesidad de la existencia de dicha política legislativa. Fundamentos sociológicos y filosóficos

Definir a la asistencia religiosa representa un esfuerzo académico inagotable porque dicha institución es aplicada en diferentes espacios o grupos sociales (hospitales, casas de familia, fuerzas policiales y castrenses, etc.). Su fundamento radica en una necesidad inherente a la condición y naturaleza humana. Es cierto que una persona es una sustancia individual de naturaleza racional y la racionalidad posibilita que exista una visión que exceda y supere el plano meramente terrenal. Curiosamente y paradójicamente, las personas cuando se enferman, cuando pierden un ser querido o cuando atraviesan algún tipo de dificultad, se aferran a cuestiones asociadas a lo eterno y a lo divino. Dicha concepción incide en cualquier ser humano, indistintamente de cualquier periodo histórico y de cualquier lugar. La vida y la muerte son dos caras de la misma moneda y en este sentido, se han planteado dos fines de la vida: uno de ellos es la felicidad y el otro es la muerte. Transitar los diferentes vaivenes de la vida muestran situaciones que incentivan a que exista un acompañamiento de un ser superior o supremo. Los argumentos esgrimidos presentan al cuerpo y al espíritu como un todo indisoluble y cuya existencia sustenta de sentido a cualquier acción humana. Considerando esta mirada general, la asistencia religiosa castrense, en lo particular, prepara, forma y acompaña a los agentes militares en su esfera estrictamente privada y trascendental.

Así, se define a la asistencia religiosa como "conjunto de medidas adoptadas por los poderes públicos para facilitar el ejercicio del derecho a la libertad religiosa en los establecimientos públicos militares, hospitalarios, asistenciales, penitenciarios y otros bajo su dependencia, así como la formación religiosa en centros docentes públicos" ${ }^{2}$. La conceptualización expuesta corrobora el inmenso océano que representa la asistencia religiosa y su funcionalidad y necesidad en la permanencia y trascendencia humana. La esencia o naturaleza define las características de cualquier ser y la faceta inmaterial atraviesa lo aspectos más profundos y esenciales. Además, los procesos de mundialización y globalización han difundido políticas materialistas que no condicen con la espiritualidad humana a tal punto que la acumulación material ha penetrado en las concepciones filosóficas

\footnotetext{
${ }^{2}$ Navarro Floria, Juan. Asistencia religiosa a la Fuerzas Armadas. Buenos Aires: Secretaría de Culto , 1997, p.32
} 
Leandro El Eter: Marco legal argentino sobre asistencia religiosa castrense. Funcionalidad y necesidad de la existencia de dicha política legislativa. Fundamentos sociológicos y filosóficos

actuales, desplazando el verdadero sentido de la vida. El capitalismo como teoría económica ha posibilitado la irrupción de una nueva cosmovisión que no necesita de una esfera espiritual para lograr sus propósitos y su aparición, ha generado pobreza material ( por la distribución inequitativa de la riqueza), espiritual y una profunda angustia, tristeza y depresión generalizada.

Por otra parte, la asistencia religiosa sólo puede ser materia del estudio del derecho eclesiástico, el cual se define como "aquella disciplina cuyo objetivo consiste en regular todas aquellas materias que vinculan los distintos aspectos del hecho o fenómeno religioso con el Estado y el ordenamiento jurídico". A pesar que el derecho eclesiástico es una disciplina joven en la Argentina, su campo de acción facilita la elaboración y formulación de la noción de asistencia religiosa como contenido prioritario de la disciplina en cuestión.

Si bien la asistencia religiosa tiene su origen en misiones militares, no es menos cierto que la institución se ha arraigado en la tradición e identidad nacional. Su formación y afianzamiento han construido los lineamientos de una cultura y costumbre que ha forjado a la independencia argentina y a la razón de ser de la identidad nacional.

En fin, la asistencia religiosa debe ser enmarcada dentro del derecho eclesiástico porque éste último contempla la totalidad de las materias religiosas y la relación del Estado y la religión. La asistencia religiosa castrense es una especie dentro del género y su conceptualización responde a motivos de comprensión de nuestra historia y tradición militar. Las costumbres y las culturales forman las identidades de los pueblos; y su maduración es parte de la construcción de los valores de una nación. Paralelamente, los diferentes Estados latinoamericanos han adoptado sistemas similares al argentino en relación a la presencia del culto católico en las fuerzas militares. 
Leandro El Eter: Marco legal argentino sobre asistencia religiosa castrense. Funcionalidad y necesidad de la existencia de dicha política legislativa. Fundamentos sociológicos y filosóficos

\section{BREVE RESEÑA HISTÓRICA. FILOSOFÍA Y RAZÓN DE SER DE LA ASISTENCIA RELIGIOSA CASTRENSE.}

La reseña de los antecedentes históricos aporta datos de importancia para una comprensión de la actual estructuración del servicio religioso en las fuerzas armadas.

Existen tres etapas bien diferenciadas y delimitadas en lo atinente a la evolución del servicio religioso castrense:

a. La primera es propia del derecho hispánico, estructurada en torno de la figura del "Patronato Regio". La designación de los capellanes militares pertenecía por concesión pontificia al Rey, quien a su vez delegaba dicha potestad en los Virreyes y Generales. Existía una "Vicaría General de los Ejércitos Españoles", que varió de denominación y que desde 1762 era inherente al Patriarca de las Indias Occidentales. Para el caso concreto del Virreinato del Río de la Plata, las funciones jurisdiccionales del Vicario General Castrense las ejercía por delegación el obispo de Buenos Aires como Teniente Vicario General.

b. Una segunda etapa, la del derecho patrio, en la que el incipiente Estado Nacional organiza una "Vicaría Castrense" creada por Leyes del 28 de junio y del 23 de julio de 1813. La ratio de estas leyes radicó en la declaración de independencia, por parte de la Asamblea el Año XIII, de cualquier autoridad religiosa que existiera fuera de su territorio constituida por presentación o nombramiento real, en nuestro caso las delegadas por el Monarca para la provisión de las capellanías militares. Las facultades canónicas las otorgaban los obispos diocesanos del territorio. Este modelo, creado por la Asamblea del Año XIII fue desmontado por la reforma impulsada por Bernardino Rivadavia, que dispuso la disolución del Vicariato Castrense, indicando que todas las personas pertenecientes al Ejército quedaban sujetas a la jurisdicción ordinaria de la autoridad 
Leandro El Eter: Marco legal argentino sobre asistencia religiosa castrense. Funcionalidad y necesidad de la existencia de dicha política legislativa. Fundamentos sociológicos y filosóficos

eclesiástica. Este Decreto en la práctica no tuvo aplicación, y el sistema del Vicariato Castrense creado por la Asamblea de Año XIII se mantuvo sin variantes hasta 1957.

c. Finalmente, en la tercera etapa, la situación antes descripta viene a ser reordenada por el Acuerdo que celebrara la Argentina con la Santa Sede, por el cual la Suprema Autoridad Eclesiástica erige para la atención espiritual de las Fuerzas Armadas un "Vicariato Castrense". Este acuerdo es el eje en torno al cual se estructura el servicio religioso ${ }^{3}$.

Las tres etapas históricas muestran cómo se implementó la asistencia religiosa desde la época colonial hasta la etapa contemporánea. La concatenación de los diferentes hechos históricos ha diseñado un esquema propicio para que dicha institución trascienda a lo largo de diferentes generaciones. La tradición, la cultura y las costumbres castrenses se han construido con los valores religiosos cristianos. Sin lugar a dudas, la realidad social muta constantemente y las normas se adaptan a las transformaciones empero, la tradición cristiana se encuentra arraigada en la cultura e identidad nacional. Por tanto, fenómenos tales como el capitalismo y la globalización no pueden interrumpir y suspender las voluntades e identidades nacionales. Amén de ello, la libertad de culto se ejerce y se respeta, pero ello no puede ser fundamento para extirpar a la creencia católica del ámbito castrense. Pretender que la religión católica no forme parte de la realidad de la defensa nacional, implica que la nación pierda su identidad, su historia y su razón de ser. Los argumentos esgrimidos son reforzados cuando se analiza a la realidad argentina con la región latinoamericana. La época colonial, las luchas independentistas y la influencia del catolicismo en las constituciones estatales han demostrado su incidencia en la cultura y educación popular.

\footnotetext{
3 Ruschi, L. M. Asistencia religiosa en las Fuerzas Armadas y de Seguridad en la República Argentina. Buenos Aires: Thomson Reuters Aranzadi, pp. 147-166
} 


\section{FUNDAMENTOS JURÍDICOS Y SOCIOLÓGICOS ACERCA DE LA EXISTENCIA DE LA ASISTENCIA RELIGIOSA CASTRENSE ARGENTINA. MARCO LEGAL. ¿EXISTE UNA VISIÓN MATERIALISTA Y ECONOMICISTA? ¿EXISTE UNA NEGACIÓN ACERCA DE LA ESPIRITUALIDAD HUMANA?}

El sistema normativo que regula la prestación del servicio religioso en el ámbito castrense y de las fuerzas de seguridad posee particularidades jurídicas que hacen a su estructuración. Es preciso mencionar que se ha señalado la inexistencia de conflictos armados para desprestigiar y desmerecer la asistencia religiosa diferenciada del resto de la población, a pesar de ello, el futuro es incierto y si bien es un objetivo estimable la paz entre las naciones, la historia de la humanidad, muestra que existen situaciones bélicas en muchas partes del planeta. Nadie puede argumentar a favor de situaciones de estas características, no obstante, forman parte de la realidad mundial. Las leyes no sólo deben tener un efecto reparador sino también preventivo y, por ende, la presencia de normas de asistencia religiosa se convierte en imperiosas ante la aparición de eventos de naturaleza bélica. Paralelamente, la presencia de referentes espirituales permite la formación en valores morales y una preparación sustentada en bienes transcendentales, es decir, que la presencia de guerras no puede transformarse en el único motivo de la asistencia religiosa como institución, sino que la plenitud terrenal y celestial atraviesa la vida de cualquier creyente.

Dentro del derecho eclesiástico argentino se pude distinguir entre lo atinente a la asistencia religiosa a las fuerzas armadas y a las fuerzas de seguridad (la Gendarmería Nacional y la Prefectura Naval) y la asistencia religiosa a los otros organismos de seguridad que cuentan con servicios de asistencia religiosa (Policía y Servicio Penitenciario). 
Leandro El Eter: Marco legal argentino sobre asistencia religiosa castrense. Funcionalidad y necesidad de la existencia de dicha política legislativa. Fundamentos sociológicos y filosóficos

El servicio religioso a las fuerzas armadas ha sido el que ha tenido más desarrollo desde la esfera del derecho, mientras que las normas referidas a las restantes fuerzas de seguridad se han limitado a seguir mayoritariamente el modelo de integración orgánica que impera en el ámbito de las fuerzas armadas, ya sea a nivel federal como provincial ${ }^{4}$.

El sistema general de asistencia religiosa en las fuerzas armadas y de seguridad ha sido influenciado por el modelo concordatario. La opción por una integración orgánica ha suscitado algunos inconvenientes y divergencias de interpretación doctrinaria especialmente en el caso del Obispado Castrense, y es lógico que haya sido así, en atención a la naturaleza practica del texto "base", a la condición de persona jurídica no estatal del mismo Obispado y a la aplicación de normas de diversa índole (concordatarias, canónicas y de derecho público estatal).

La simple incorporación orgánica de clérigos en las fuerzas de seguridad no incluidas en el régimen del Acuerdo de 1957 no provoca mayores dificultades, del mismo modo que no lo provocan las asignaciones de capellanes en institutos sanitarios, educativos o entidades administrativas. La autoridad territorial designa al capellán solicitado por la Administración, quien lo incorpora o contrata de acuerdo a su propio régimen.

Legalmente, no se impide que se establezcan medios idóneos para brindar el servicio religioso a los militares y agentes de las fuerzas de seguridad no católicos. Dicho lineamiento es reforzado por el principio de la libertad de culto que tiene raigambre constitucional.

En la práctica, y aún sin marco normativo, existe la posibilidad que los militares pertenecientes a confesiones distintas de la Iglesia Católica soliciten al encargado del Servicio

\footnotetext{
${ }^{4}$ Navarro Floria, Juan. Derecho y Religión. Derecho Eclesiástico Argentino. Buenos Aires: Universidad Católica Argentina, 2014, pp. 32-65
} 
Leandro El Eter: Marco legal argentino sobre asistencia religiosa castrense. Funcionalidad y necesidad de la existencia de dicha política legislativa. Fundamentos sociológicos y filosóficos

Religioso (los Capellanes Mayores o los Capellanes Castrenses ) que arbitre los medios para que la asistencia religiosa sea brindada de acuerdo a las creencias personales, facilitando un lugar adecuado para las celebraciones que fuere menester y coordinando los horarios y desplazamientos dentro de las unidades militares.

Indagar jurídicamente acerca de la necesidad de la asistencia religiosa y de la presencia de los capellanes en las fuerzas armadas es responder a las necesidades religiosas de los grupos sociales castrenses. Otro planteamiento es afín a qué modelo es el más idóneo para lograr que la asistencia espiritual, al militar creyente, sea lo más efectiva posible. Muchas veces, la letra de la ley es fría al no poder insertase dentro de un encuadre fáctico, pero, los hechos sociales han incentivado la presencia de un marco jurídico tendiente a satisfacer las necesidades e intereses del grupo social teniendo en cuenta la teoría tridimensionalista del derecho. Dicha teoría sostiene que el derecho no se encuentra constituido estrictamente por normas sino que el derecho se encuentra formado por hechos, normas y valores.

Hay creyentes que cuestionan la presencia de sacerdotes en la milicia. Laicos, sacerdotes o incluso algún obispo llegan a plantearse si esa presencia, en un medio preparado para la guerra y si es compatible con la fe y el evangelio. Por otra parte, algunos militares piensan que, con la presencia de capellanes católicos, puede existir un predominio de la Iglesia católica en la institución militar, con la consecuente discriminación de otras confesiones religiosas. Todos los cuestionamientos son refutados de una manera sencilla y de acuerdo a la realidad jurídica y militar. Es incuestionable que el cristianismo es una religión con amplia difusión y aceptación, pero, ello no es impedimento para que se practique otra religión o para que se opte por la no practica de ningún culto. La decisión recae en cabeza de la persona y ésta no puede ser coaccionada a subordinarse a una convicción que no condice con sus creencias. Bajo ningún punto de vista, existe discriminación, sino que existe una libertad lo suficientemente amplia para la elección de la opción más adecuada de acuerdo a la intimidad de cualquier agente militar. Complementariamente, existe una suerte 
Leandro El Eter: Marco legal argentino sobre asistencia religiosa castrense. Funcionalidad y necesidad de la existencia de dicha política legislativa. Fundamentos sociológicos y filosóficos

de acompañamiento ético o moral que representa otra forma de acompañamiento o seguimiento. Situaciones asociadas al ateísmo, agnosticismo e indiferencia forman parte de la realidad del cuerpo militar y son respetadas porque hacen a la libertad de pensamiento, de conciencia y de expresión.

Existe una necesidad de asistencia religiosa del personal castrense, en la medida que lo requieran o soliciten. Así, se deben garantizar los siguientes derechos: respeto de la libertad de cultos; asistencia a los enfermos y a los mayores de edad en necesidad de asistencia religiosa; tolerancia religiosa.

La prestación de asistencia moral y atención espiritual y religiosa es una necesidad inherente a la persona humana porque las personas poseen cuerpo y alma. La universal frase platónica "el cuerpo es cárcel de alma" es sinónimo de trascendencia .

Facilitar la asistencia espiritual de las diversas congregaciones religiosas existentes en todo el territorio nacional forma parte de una exigencia espiritual dada la naturaleza humana y noción de vida eterna.

No sólo dicha asistencia religiosa es propia de las fuerzas armadas, sino que en la actualidad, los capellanes, encargados del servicio religioso, ayudan a los pacientes y sus familiares en los hospitales a sobrellevar sus enfermedades, problemas y aún la muerte. En ciertas situaciones, forman parte del equipo, colaborando con los médicos, enfermeras, psiquiatras y trabajadores sociales. El rol del capellán es el de dar asistencia espiritual a los familiares del paciente y al personal, con el objeto de brindar apoyo especial en una situación hospitalaria.

En cuanto a legislación interna, cabe destacar que el artículo 14 de la Constitución Nacional enumera derechos de los habitantes de la Nación, entre ellos el de profesar libremente su culto, lo que significa que todo habitante argentino posee derecho a 
Leandro El Eter: Marco legal argentino sobre asistencia religiosa castrense. Funcionalidad y necesidad de la existencia de dicha política legislativa. Fundamentos sociológicos y filosóficos

manifestar y llevar a cabo su creencia en cuestión. No obstante, el artículo aclara conforme a las leyes que reglamenten su ejercicio, es decir que éste y los demás derechos anunciados deben reglamentarse por leyes. La libertad no puede despegarse de la naturaleza humana dado que los hombres nacen libres, y expresiones filosóficas tales como el liberalismo, el humanismo y el renacimiento forman parte de las manifestaciones humanas que trascienden cualquier tipo de fronteras. Vale decir, que la libertad de culto no puede ser confiscada ni violada porque es un derecho natural y su cercenamiento es sinónimo de una injusticia.

A su vez, el artículo 20 de la Carta Magna explicita los derechos para los extranjeros $y$, entre los que enumera, se halla el derecho a ejercer libremente su culto, lo que alude que el extranjero puede ejercer su religión, mientras respete las leyes reglamentarias y la Constitución.

A nivel internacional, el artículo 18 de la Declaración Universal de los Derechos Humanos expresa "toda persona tiene derecho a la libertad de pensamiento, de conciencia y de religión", este derecho incluye la libertad de cambiar de religión o de creencia, así como la libertad de manifestar su religión o su creencia, individual y colectivamente, tanto en público como en privado; por la enseñanza, la práctica, el culto y la observancia 5 .

Por otra parte, los artículos 18 y 27 del Pacto Internacional de Derechos Civiles y Políticos también se encuentran en línea con la libertad de culto, dado que garantizan a las minorías religiosas el derecho a confesar y a practicar su religión; el artículo 14 de la Convención de los Derechos del Niño también sostiene esta postura6 ${ }^{6}$.

La asociación de la Iglesia Católica con los cuerpos castrenses a los fines de su asistencia religiosa, ha sido invariable en los más diversos lugares y épocas. En nuestro

\footnotetext{
${ }^{5}$ La Declaración Universal de los Derechos Humanos puede complementarse con otros tratados. Del mismo modo, la resolución 36/55 regula la no discriminación; y, en definitiva, la tolerancia y la diversidad son manifestaciones de la libertad de culto.

${ }^{6}$ Tanto la Constitución Nacional y los tratados internacionales con jerarquía constitucional han diseñado un "sistema protectorio" de la libertad de culto y del respeto por las diferencias.
} 
Leandro El Eter: Marco legal argentino sobre asistencia religiosa castrense. Funcionalidad y necesidad de la existencia de dicha política legislativa. Fundamentos sociológicos y filosóficos

continente y en las colonias hispanas, existen testimonios y documentos históricos , que dan fe del acompañamiento religioso en las misiones militares de conquista y en las gestas independentistas en diversas regimientos, campañas y cruzadas $^{7}$. Si bien en principio dependían solamente de sus obispados, los sacerdotes y religiosos demostraron presencia y prestaron asistencia religiosa a militares. Bajo el papado de Pío XII en 1951, que se emitió una instrucción que mandaba la constitución de Vicariatos castrense en diversas regiones. Dicho instrumento ya se encontraba vigente al momento de la negociación del tratado entre Argentina y el Vaticano en 1.957 para la estructuración institucionalizada del primer vicariato castrense. Las negociaciones entre ambos estados se iniciaron desde 1941 y culminaron en Roma en 1957, siendo ratificado por nuestro país el 8 de Julio del mismo año por el decreto ley 7.623 , luego reglamentado por el decreto $12.958 / 57^{8}$ durante la presidencia de Pedro Eugenio Aramburu. Su diseño se adaptaba a la previsión del ejercicio del derecho del patronato por parte del Poder Ejecutivo y declaraba que se erigía para el cuidado espiritual de las fuerzas militares de aire mar y tierra, que en el orden militar y jurídico el vicariato dependería directamente del Presidente de la Nación y designaba a tres capellanes mayores (uno para cada fuerza) y otros sacerdotes para escalas inferiores. En 1966 a través de un acuerdo bilateral entre el Argentina y la Santa Sede aprobado legislativamente por la ley 17.032, se ratifica la vigencia del Convenio firmado en 1957.

Por la Constitución Apostólica Spirituali Militum Curae expedida por Juan Pablo II, la Santa Sede reforma unilateralmente la estructura acordada, llegándose a una readaptación del texto del primer acuerdo, a las nuevas previsiones a través de una acuerdo concertado con el Vaticano en 1992, a través del intercambio de notas reversales con el Vaticano y el reconocimiento del Obispado Castrense por el Decreto 1.526 del mismo año, y dispone una organización encabezada por un Obispado Castrense, un obispo auxiliar ratificando la existencia de capellanías mayores y subcapellanías dependientes en las tres Fuerzas Armadas.

\footnotetext{
7 Carbía, Rómulo Carbia. La Revolución de Mayo y la Iglesia. Buenos Aires: Nueva Hispanidad, 2005, p.65

8 El Decreto Nacional 12958/57 ha instituido un " esquema legislativo" que tiene por objeto la preservación de la asistencia religiosa dentro de las Fuerzas Armadas.
} 
Leandro El Eter: Marco legal argentino sobre asistencia religiosa castrense. Funcionalidad y necesidad de la existencia de dicha política legislativa. Fundamentos sociológicos y filosóficos

La síntesis histórica expuesta nos demuestra la importancia que cumplía para las fuerzas militares el acompañamiento religioso de sacerdotes católicos. Quedaron en la historia las campañas de conquistas y cruzadas en las que por lo extenso de las misiones era previsible que los militares afectados, así como afrontarían padecimientos y odiseas, no recibirían servicio de asistencia religiosa por mucho tiempo, si no eran acompañados por los mismos sacerdotes castrenses. Hoy la realidad fáctica nos demuestra que amen que los medios de transporte y de comunicación facilitan la celeridad y los desempeños de las más diversas actividades laborales, el militar es un ciudadano más, que todos los días más allá de sus funciones, convive en la sociedad como uno más de sus miembros con los mismos privilegios y responsabilidades y que salvo situaciones excepcionales, puede concurrir a rendir culto a la religión de sus convicciones sin que por ello tenga que aprovechar la existencia de cuerpos sacerdotales especialmente constituidos dentro de los regimientos. La faz jurídica señala que por la vigencia de tratados internacionales de jerarquía constitucional (art. 75 Inc. 22 de la C.N.), se deben respetar no solamente la libertad de conciencia sino la libre opción de creencia y hasta el señorío para no ser obligados directa o indirectamente a manifestarla a terceros.

Se pretende garantizar la libertad religiosa y el albedrío espiritual para que todos los empleados de las fuerzas armadas y de seguridad, por el solo hecho de que tengan que cumplir disposiciones superiores, no sean obligados directa o indirectamente a través de ordenes conminativas, a participar de ceremonias de cultos con los que no comulga o en los que se deje traslucir a que culto adhieren. Ello porque no solamente debe respetarse la libertad de religión (elegir, profesar o cambiar de credo ), sino que también las creencias de cada persona deben apreciarse como inherentes al fuero interno al ámbito de la intimidad y por ende deben ser entendidas como inviolables, si es que el titular no manifiesta su voluntad de exteriorizarlas.

En fin, el materialismo histórico marxista ha pretendido articular políticas tendientes a erradicar a la asistencia religiosa de la esfera social y su desaparición puede ocasionar una 
Leandro El Eter: Marco legal argentino sobre asistencia religiosa castrense. Funcionalidad y necesidad de la existencia de dicha política legislativa. Fundamentos sociológicos y filosóficos

"anarquía social", sumergiendo a la nación en una profunda angustia, tristeza y desesperanza por motivo que el conocimiento de la divinidad es una necesidad que excede a lo aspectos estrictamente materialistas o economicistas. La negación a la espiritualidad humana ha pretendido que el sistema capitalista gobierne las vidas de las personas. Se trata de una visión alimentada con la acumulación material y desprovista de una filosofía de vida con una mirada cristiana. Estas teorías capitalistas han tenido su influencia en los frustrados intentos por reemplazar a las instituciones religiosa por instituciones laicistas.

\section{PRETENSIONES LEGISLATIVAS FRUSTRADAS PARA DEROGAR AL INSTITUTO DE LA ASISTENCIA JURÍDICA CASTRENSE. IRRUPCIÓN DE TENDENCIAS CONTRARIAS A LA LIBERTAD RELIGIOSA Y A LA HISTORIA E IDIOSINCRASIA NACIONAL.}

En 2009, se denunció el Acuerdo de 1957 del 28 de junio de 1957 aprobado por Decreto 7623/ 57 reglamentado y aprobada las modificaciones por Decreto 1526/1992 con la Santa Sede sobre Jurisdicción castrense y asistencia religiosa a las fuerzas armadas. El objeto de la presentación de dicho proyecto de ley fue derogar la asistencia religiosa castrense. Dicho objetivo se frustró y la institución de referencia continua vigente.

Se pretendía que cesen en sus funciones el obispo castrense, el obispo auxiliar castrense, los capellanes mayores, los sacerdotes militares de cada una de las fuerzas armadas y quienes desempeñen funciones eclesiales análogas en las fuerzas de seguridad. 
Leandro El Eter: Marco legal argentino sobre asistencia religiosa castrense. Funcionalidad y necesidad de la existencia de dicha política legislativa. Fundamentos sociológicos y filosóficos

Del mismo modo, se pretendía que los miembros activos del ámbito castrense y las fuerzas de seguridad, sean cuales fueren su modalidad de contratación, gozan de la libertad de elegir, practicar y profesar su culto religioso. Ninguno de ellos podrá ser obligado a declarar sus creencias religiosas ni a participar de la celebración de ceremonias litúrgicas en actos oficiales.

Este instrumento internacional fue el fruto de un largo proceso iniciado en 1915, a instancias del presidente Victorino de la Plaza; retomado en 1935 a la clausura del Congreso Eucarístico Internacional celebrado en Buenos Aires; desarrollado a partir de 1945 y finalizado con la firma del Acuerdo en el Palacio Apostólico.

El Acuerdo fue actualizado a las prescripciones de la nueva normativa canónica (las pertinentes disposiciones del Concilio Vaticano II, el Código de Derecho Canónico promulgado en 1983 y principalmente la Constitución Apostólica "Spirituali Militum Curae" sobre los Ordinariatos Castrenses de 1986) por medio de unas Notas Reversales intercambiadas el 21 de abril de 1992.

Con la firma el 28 de junio de 1957 del Acuerdo celebrado por la Santa Sede y la República Argentina sobre asistencia religiosa a las Fuerzas Armadas se obtienen dos resultados: en primer término, la erección formal de una estructura pastoral centralizada dedicada exclusivamente a la asistencia religiosa a la fuerzas armadas; en segundo lugar, la adopción - por voluntad de ambas partes contratantes - de un modelo de integración orgánica de naturaleza concordataria o pacticia para el Servicio Religioso Castrense, con las particularidades y dificultades que surgen de la armonización y conjunción de las normas aplicables promulgadas por esas dos sociedades (Iglesia y Estado). La efectiva integración se efectúa con la promulgación del Decreto-Ley № 12.958/1957 que crea el “Sistema Orgánico del Vicariato Castrense" ${ }^{\prime 9}$.

\footnotetext{
${ }^{9}$ Hanna, Marta. Obispado Castrense para las Fuerzas Armadas y de Seguridad en la República Argentina. Buenos Aires: Calir, 2007, pp. 213-218
} 
Leandro El Eter: Marco legal argentino sobre asistencia religiosa castrense. Funcionalidad y necesidad de la existencia de dicha política legislativa. Fundamentos sociológicos y filosóficos

El Acuerdo trata los siguientes temas en sus dieciséis artículos: Erección del Vicariato Castrense (artículo I), Composición y sistema de nombramientos (artículos II a VIII), Poder Disciplinario (artículos IX y XIV a XV), Jurisdicción (artículos X a XII) y Servicio Militar (artículo XIII).

El otro problema planteado con relación al artículo I del Acuerdo se refiere a la extensión del servicio religioso. En efecto, el Acuerdo no distingue entre miembros de las Fuerzas Armadas católicos y no católicos, como sí lo hacen otros acuerdos celebrados por la Santa Sede. El artículo X del Acuerdo de 1957 dice expresamente que la jurisdicción del Vicario Castrense se extiende "a todos los militares de Tierra, Mar y Aire".

Hay que destacar que los Acuerdos en esta materia celebrados con posterioridad al Concilio Vaticano II y a la promulgación del Código de Derecho Canónico de 1983, han modificado esta posición y los Acuerdos sobre asistencia religiosa especifican que se refieren a los fieles católicos de dichas fuerzas. Juan Gregorio Navarro Floria sostiene que por aplicación de la Constitución Spirituali Militum Curae, aplicada por vía de remisión por imperio de las Notas Reversales de 1992, este distingo queda salvado.

En materia de jurisdicción, otra norma - esta vez de las Notas Reversales - que tiene incidencia directa sobre el derecho eclesiástico del estado es el artículo VI, ya que al establecer que el Obispado Castrense conservará la jurisdicción que tuvo el Vicariato Castrense, legitima el servicio que éste prestaba en las Fuerzas de Seguridad en otro tiempo "militarizadas" y que en principio deberían quedar excluidas en cuanto a su integración dentro del aparato estatal por fuerza del Acuerdo ${ }^{10}$.

10 Padilla, Norberto. El Acuerdo entre la Nación Argentina y la Santa Sede del 28 de junio de 1957 a 40 años de su firma. Buenos Aires: Secretaría de Culto , Buenos Aires, 1997, pp.7-29 
Leandro El Eter: Marco legal argentino sobre asistencia religiosa castrense. Funcionalidad y necesidad de la existencia de dicha política legislativa. Fundamentos sociológicos y filosóficos

En 1966, se solicitó al Ministerio de Relaciones Exteriores y Culto prestar su aprobación al Acuerdo suscrito el 10 de octubre del año en curso, entre la Santa Sede y la República Argentina.

El acuerdo citado tiende a asegurar a la Iglesia Católica la libertad necesaria para el cumplimiento de su alta misión espiritual dando así satisfacción al pedido del Concilio Vaticano II.

Las demás confesiones religiosas gozan de la facultad de nombrar sus pastores, determinar sus jurisdicciones territoriales, y comunicarse, sin trabas, con sus autoridades radicadas en el extranjero sin ninguna intervención del Estado.

Por último, cabe señalar que el Acuerdo entre la Santa Sede y la República Argentina, suscrito en Buenos Aires, el 10 de octubre de 1966 fue aprobado ${ }^{11}$.

En fin, no es menos cierto que dicha estructura religiosa no sólo se encuentra legislada en la Argentina sino en la región americana, también. Brasil, Chile, Bolivia, Uruguay y Paraguay, entre otros Estados, han creado un sistema similar y su fundamento tiene orígenes comunes. Existe una historia y una cultura compartida entre los pueblos americanos; y el objeto de la permanencia de dicha institución posee un sentido de conservación de una tradición que ha sido transmitida de generación en generación; dicho proceso de afianzamiento de la asistencia religiosa no es casualidad sino causalidad; la influencia europea ha penetrado en la comunidad latinoamericana y existen valores que han perdurado a lo largo del tiempo.

\footnotetext{
${ }^{11}$ Agar, José T. Martín. Raccolta di Concordati 1950-1999. Ciudad del Vaticano: Libreria Editrice Vaticana, 2000, pp. $46-47$
} 
Leandro El Eter: Marco legal argentino sobre asistencia religiosa castrense. Funcionalidad y necesidad de la existencia de dicha política legislativa. Fundamentos sociológicos y filosóficos

\section{CONCLUSIÓN}

Considerando los argumentos esgrimidos, puede concluirse que el marco jurídico argentino sobre asistencia religiosa castrense forma parte de una necesidad y exigencia humana. El contraste de aspectos históricos, sociológicos, jurídicos y religiosas muestran que las fuerzas armadas requieren de asistencia religiosa. Dado que las personas poseen cuerpo y alma, la asistencia religiosa condice con la visión trascendente de cualquier ser humano toda vez que las necesidades de la naturaleza humana no se satisfacen sólo con aspectos materiales, sino que existe una tendencia que supera y excede lo terrenal.

Amén que las normas internas se circunscriben a la religión cristiana, no existe ningún tipo de impedimento legislativo para profesar otros tipos de religiones y cultos. La libertad religiosa es un derecho constitucional y las normas inferiores dictadas en consecuencia, se subordinan a los preceptos de la Carta Magna y de los tratados internacionales con jerarquía internacional.

Hubo intentos legislativos infundados de derogar las normas que regulan el instituto de referencia. Es menester señalar que existen críticas en torno a que el cristianismo es un monopolio religioso, pero ello, no es cierto porque cualquier persona es respectada de acuerdo a sus convicciones éticas, morales y religiosas. Ninguna norma obliga a ninguna persona a subordinarse a un culto determinado, sino que el sistema argentino promueve la libertad de conciencia y religión como valores supremos. Conjuntamente, la libertad de pensamiento y expresión son inherentes a la condición humana.

La asistencia religiosa, como institución jurídica, no puede ser sustituida, reemplazada ni derogada porque su existencia posibilita una contención y reguardo espiritual imprescindible. Existen leyes positivas que se modifican o derogan, sin embargo, las leyes naturales y divinas no se modifican y su existencia es atemporal en el sentido que no es susceptible de ningún tipo de transformación ni mutación. Las leyes naturales son 
Leandro El Eter: Marco legal argentino sobre asistencia religiosa castrense. Funcionalidad y necesidad de la existencia de dicha política legislativa. Fundamentos sociológicos y filosóficos

inherentes a la condición humana y la asistencia religiosa es una necesidad espiritual. A pesar que el origen y sentido de dicha institución fue realizar una tarea de acompañamiento espiritual durante situaciones bélicas, no es menos cierto que, en la actualidad, su presencia permite acompañar a los militares en sus labores habituales. Dicha asistencia forma parte de la vida de cualquier persona, por lo que carece de sentido derogar dicho instituto en la órbita castrense.

La historia y la tradición católica se han transmitido de generación en generación y su negación implica cercenar un ámbito personal, íntimo y privado del ser humano . Empero, el multiculturalismo, la tolerancia y el respeto por las diferentes religiones representan una conquista social y legal, que coexiste con la presencia de normas que regulan a las instituciones católicas como consecuencia de un afianzamiento cultural y de una tradición histórica.

\section{BIBLIOGRAFÍA}

- Agar, José T. Martín. Raccolta di Concordati 1950-1999. Ciudad del Vaticano: Libreria Editrice Vaticana , 2000

- Carbía, Rómulo Carbia. La Revolución de Mayo y la Iglesia. Buenos Aires: Nueva Hispanidad, 2005

- Hanna, Marta. Obispado Castrense para las Fuerzas Armadas y de Seguridad en la República Argentina. Buenos Aires: Calir, 2007

- Navarro Floria, Juan. Derecho y Religión. Derecho Eclesiástico Argentino. Buenos Aires: Universidad Católica Argentina, 2014

- Navarro Floria, Juan. Asistencia religiosa a la Fuerzas Armadas. Buenos Aires: Secretaría de Culto , 1997 
Leandro El Eter: Marco legal argentino sobre asistencia religiosa castrense. Funcionalidad y necesidad de la existencia de dicha política legislativa. Fundamentos sociológicos y filosóficos

- Padilla, Norberto. El Acuerdo entre la Nación Argentina y la Santa Sede del 28 de junio de 1957 a 40 años de su firma. Buenos Aires: Secretaría de Culto , Buenos Aires, 1997

- Ruschi, L. M. Asistencia religiosa en las Fuerzas Armadas y de Seguridad en la República Argentina. Buenos Aires: Thomson Reuters Aranzadi

- Constitución Nacional Argentina

- Convención Internacional sobre los Derechos del Niño

- Pacto Internacional de Derechos Civiles y Políticos

- Declaración sobre la eliminación de todas las formas de intolerancia y discriminación fundadas en la religión o convicciones (Declaración de 1981)

- Leyes del 28 de junio y del 23 de julio de 1813

- Decreto- Ley 7623 reglamentado por Ley 12958/1957

- Ley $17032 / 1966$

- Decreto 1526/1992

- Juan Pablo II, Constitución Apostólica Militum curae (21 de abril de 1986)

- Concilio Vaticano II 